\section{IRRADIATION AND THE LEUKAEMIAS.} A.V INDEX TO MORE SLCCESSFUL TREATMENT.

\section{F. A. KNoTT, M.D., M.R.C.P., D.P.H.,} HAEMATOLOGIST TO GUY'S HOSPJTAL; AND

W. L. WATT, C.M.G., M.D., SURGEON IN CHARGE OF DEEP THERAPY DEPARTMENT, GUY'S HOSPITAL.

Treatment of the leukaemias by deep ray therapy has several distinct advantages over the older methods of irradiation. ${ }^{1}$ The chief of these are:

1. The danger of dermatitis is reduced to a minimum.

2. After the preliminary stay in hospital the patient can usually return to work, and need only occasionally report for examination or a short treatment, the interval in some cases being many months.

3. Patients will occasionally still respond well to deep therapy when further reduction of the white count is found to be impracticable by ordinary $x$ rays.

\section{Dosage Control.}

In the past, dosage control has largely depended upon the rise and fall of the actual white cell count in the blood, but this was often found to be misleading, since it did not explain why in some cases the effect of irradiation was beneficial from the start, while in others, with more or less identical blood counts, and subjected to exactly the same dosage, there was marked constitutional reaction, and occasionally severe delayed effects with infective complications.

The real need, therefore, has been for some more reliable guicle to dosage control. With this end in view we have during the last eighteen months attempted to devise and utilize some simple and safe haematological test which would give the desired information.

In a previous note ${ }^{2}$ we described our carlier results when directly estimating the phagocytic power of leucocytes in leukacmic patients; in the present note it is our object to indicate, from the results of controlling in this way the treatment of sixteen cases of leukaemia, the assistance which we believe can be derived from estimating the number of actively phagocytic leucocytes in the blood as compared with the total white cell count.

\section{The Phagocytic Test.}

The technique of the test in its simplest form has been described in Guy's Hospital Reports ${ }^{3}$ but it is clear that, instead of observing the phagocytosis of washed staphylococci as adopted in our experiments, any suitable particulate material may be used, provided conditions are carefully standardized. If it is considered preferable to concentrate the leucocytes, this may be done as in the familiar opsonic index technique, or by Ponder's method of causing the cells to collect on, and adhere to, a cleain glass slide. Whichever technique is preferred, we would emphasize that the point to be determined before the patient is irradiated is the number of white cells per volume of the blood, which have, when in contact with his own serum, a normal fully effective phagocytic power.

By making this estimation at the start, and at intervals during treatment, it seems possible to obtain direct evidence in answer to the following questions :

1. Is irradiation likely to produce undue reaction, clinically or haematologically?

2. When treatment is once started, how long, and how strongly, may it be continued?

3 . What is the prospect of a good response and return to a more normal blood picture?

4. When should irradiation be repeated?

Results of Application of Test.

We have recorded our results, not as in the opsonic index, in which the average number of organisms per leucocyte is recorded, but as the percentage of cells which contain more than twenty bacteria, between twenty and ten bacteria, less than ten bacteria, and none at all. In a normal person at least 85 per cent. of the polymorphs are found to contain more than twenty cocci, and extremely few are non-phagocytic. For simplicity, only the percentages of leucocytes falling in the strongly phagocytic group will be referred to in the following summary, because in practice we have found that it is necessary to consider only the percentage of polymorphs which are at any particular time phagocytically normal.

In all our cases the myeloblasts and myelocrtes have been entirely non-phagocytic, and most of the immature leucocytes have been markedly deficient in this respect. We have found in each case that the number of actively phagocytic cells is lower in the haematologically more severe cases, in agreement with the gencrally accepted dictum that the severity of a case of leukaemia is to be judged by the percentage of immature cells present, rather than the actual increase in the total white count. As Piney ${ }^{5}$ has pointed out, many cases of splenomedullary leukaemia contain many times the normal number of normal polymorphs, and the results of the phagocytic test fully bear this out. In early cases, with very high polymorph counts, phagocytosis may be very active, but as the disease progresses the percentage of phagocites slowly falls.

It will be generally agreed that, during irradiation of leukaemias, the most lasting results, and the most rapid initial fall, in the total white count are obtained in those cases in which the percentage of frankly immature cells is relatively low. Disappointing results are most frequently associated with the more advanced and myeloblastic cases. Between these extremes many intermediate cases occur in which, from clinical and haematological considerations, it is most difficult to forecast the response to irradiation treatment. In these we find the phagocytic test definitely helpful. The higher the percentage of actively phagocytic neutrophils present at the outset of, and during, irradiation, the more quickly does the blood picture improve and the spleen decrease in size, and the less likely is reaction to ensule.

Thus in a series of ten patients with splenomedullary leukaemia, all of whom responded extremely well, suffered no significant reaction, and are all following their normal occupation at the present time; the average total white cell count at the start was 208,000 per c.mm., of which 82,500 were actively phagocytic; six to nine months later the average total white count was 14,500 per c.mm., of which 7,200 were actively phagocytic. Two cases of lymphatic leukaemia, sinilarly tested, gave initial counts of 45,000 white cells per c.mm. (12,000 phagocytes) and 70,000 white cells per c.mm. (14,000 phagocytes) respectively; four to six months later the corresponding white counts were 25,000 per c.mm. (6,000 phagocytes) and 16,000 per c.mm (4,400 phagocytes). It will be noted that at no time did the total phagocytic count in these cases fall to or below that met with in a normal blood-namely, about 4,000 per c.mm. It seems that during, and for some time after, irradiation a good supply of fixed and circulating phagocytes is necessary for satisfactory resolution of the tissue zones damaged by the rays, and the phagocytic test appears to be a satisfactory method of estimating this supply.

If we now turn to an actual summary of the first three cases of leukaemia given below, which have shown marked constitutional reaction and responded badly to deep therapy treatment, they are seen to have a relatively low phagocytic power. Case III illustrates how successful treatment of this type of case may be achieved by the use of relatively small doses of rays, and Case IV shows how the phagocytic test may give guidance as to the possibility of successful irradiation, in spite of the patient's general condition being extremely bad.

\section{CASE I}

A woman, aged 50. Splenomedullary type. On September 30th, 1929, haemoglobin 51 per cent. Total white count 13,200 per c.mm. (polyinorphs 25 per cent., myelocytes 8.5 per cent., and myeloblasts 0.5 per cent.). Total active phagocytes only 490 per c.mm. After two irradiations of spleen: white count 12,800 per c.mm., with a total phagocyte count of only 350 per c.mm. Very marked reaction, vomiting, highly toxic state, and marked pyrexia-maximum $104.5^{\circ} \mathrm{F}$. No reduction in size of spleen. Niclein injections given. Temperature slowly fell, and phagocytes rose to 550 . No improvement in blood count. 
CASE II.

A man, aged 53. Splenomedullary. Total white count 120,000 per c.mm. At first (April 18th, 1927) good response to deep therapy; spleen reduced; gain in weight; count fell to $30,0 \mathrm{C} 0$ per c.mm By September 3rd, 1928, white count again rose to 105,000 per c.mm. and, in spite of further irradiation, was still 164,000 on February 20th, 1929. No reaction occurred in 1928 during occasional irradiation, but slight fall of white count recorded after each irradiation. At the beginning of 1929 a steady fall of phagocytes began, until, on November 12th, there were less than 1,000 phagocytes per c.mm., and a total white count of 200,000 per c.mm. (myelocytes 40 per cent., polymorphs 32 per cent., myeloblasts 0.5 per cent.). Spleen very large. The patient at this point became markedly intolerant to deep therapy, and only medical treatment was possible subsequently. He died early in 1930 .

\section{Case III.}

A man, aged 36, with typical splenomedullary leukaemia, was first seen on July 8th, 1929. Total white count 115,000 per c.mm. (myelocytes 30 per cent., polymorphs 42 per cent., nearly all phagocytic). Full doses deep therapy. White count fell to 8,500 per c.mm., spleen much reduced (September 16th). Three months later white count again rising, and, in spite of occasional irradiation, count on March 29th, 1930, was 170,000 ; spleen very large, marked oedema of legs. Phagocytes now only 4,000 per c.mm. compared with about 40,000 when first seen. Subsequent irradiation produced very marked constitutional reaction, vomiting, and pyrexia. A moderate fall resulted in the white count, but this immediately rose again to 120,000 . Evidently response to deep therapy was beginning to fail, but by using smaller doses of deep therapy-one-quarter usual size-it has been possible up to the time of writing to avoid serious reaction and to prevent the white count from rising far above 100,000 , but it-is impossible to bring the count down as before.

\section{CaSe IV.}

M. H., aged 44. Typical splenomedullary case. Total white count 400,000 per c.mm. (myelocyles 42 per cent., polymorphs 30 per cent.) on June 14th, 1930. Marked oedema and ascites, much loss of weight, complete prostration. Before admission splenic irradiation from Coolidge tube had produced reaction and some burns, so discontinued. When admitted, total phagocytes 90,000 per c.mm. Therefore, in spite of previous reactions, it was decided to give deep therapy in full doses. No reaction followed. On July 12th patient walking, no oedema or ascites, spleen much reduced; white count total 100,000 per c.mm., of which 60,000 were phagocytic. Patient is still quite tolerant of deep therapy, and white count is remaining below 100,000. This is an example of relatively high phagocytic power as indicating the possibility of full irradiation, in spite of extremely poor initial general condition.

\section{Commentary.}

From these cases, taken as typical of the many now treated, we think it may reasonably be suggested that determination of the number of active phagocytes present at any given time provides definite indications as to the dosage and the prognosis in general.

In the past it was customary during irradiation simply to guard against the development of a leucopenia. The phagocytic test appears to be capable of providing a definitely earlier warning. The total number of active phagocytes in a normal blood tested by our technique is about 4,000 per c.mm., and, since adopting the rule that cases, leukaemic and others, should be irradiated very lightly, or not at all if their blood contained less than 2,000 phagocytes per c.mm., no severe reactions of any kind have been encountered. It is noteworthy that at the time this investigation was started five other patients were available for blood examination who were markedly intolerant to deep therapy. Three responded by marked constitutional reaction; one had developed broncho-pneumonia, and one streptococcal skin lesions. In each case the number of normally active phagocytes in the blood was found to be 1,000 per c.mm. or less.

In selecting cases for treatment, observation of a good phagocytic power may allow one to discount other factors, such as poor general condition or septic complications, which might otherwise cause hesitation in applying vigorous irradiation.

\section{Extension of Method.}

In conclusion, it may be added that, in practice, application of this method of dosage control has not been limited to the leukaemias. Since October, 1929, all cases of diffuse glandular enlargement, neoplasm, etc., for which deep therapy treatment was considered likely to be of benefit but where the general condition was not good, have been tested in this way. By setting the standards described above it has been found possible to reduce constitutional reaction to a minimum, and to irradiate successfully several cases which from general considerations might have been thought unlikely to tolerate the rays.

\section{Summary.}

1. The importance of an adequate supply of active phagocytes in the blood of a patient undergoing deep $x$-ray treatment is emphasized.

2. In leukaemias the higher the percentage of active phagocytes the better the prognosis, and the more ready their response to irradiation.

3. It is suggested that the number of active phagocytes in the blood of a patient undergoing deep $x$-ray treatment should not. be allowed to fall below 2,000 per c.mm.

Our thanks are due to the honorary visiting staff of Guy's Hospital for their kindness and help in permitling and facilitain the repeated examination of the various patients under observa tion, and especially to Di. A. F. Hurst, Dr. E. P. Poulton, Dr. N. Mutch, Dr. J. A. Ryle, and Dr. A. H. Douthwaite, under whose care the patients referred to were admitted.

1 Watt, W. I., and Carter-Braine, J. F.: Lancet, 1925, i, 6.

2 Knott, F. A., and Watt, W. L. : British Medical Journal, 1929, i, 542

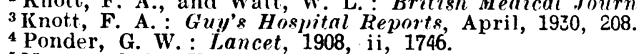

5 Mayneord, W. V.; and Piney, A. : Brit. Journ. of Ralliol., 1928, 3.

\section{TREATMENT OF OCULAR DISEASES WITH MERCUROCHROME.}

\section{E. R. CHAMBERS, F.R.C.S.Ed., D.O.M.S.,} OPHTHALMIC SURGEON, BRISTOL ROYAL INFIRMARY.

Frw medical men seem to realize what a useful drug we have in mercurochrome for certain ocular diseases. It is no new drug, having been used in Bristol for the last four years, so that a vast number of cases have been treated with it. My attention was first drawn to it hy the fact that my surgical colleagues had proved it to be a useful antiseptic in bladder cases, and had found it practically non-irritating. In our hands, in the treatment of certain eve diseases, it has proved to be a very powerful antiseptic, and the irritation caused by it in the majority of cases is negligible. Its one disadvantage is its red colour, as this will stain the skin for a few days, but this can be obviated if, immediately after its application to the eye, any remaining on the skin is wiped off with moist cotton-wool. It is used in the form of drops made of a 1 per cent. solution, as an ointment of the same strength, or as a paint of a 1 or 2 per cent. strength.

\section{Uses in Conjunctivitis.}

The drug is of service in all types, and by far the leest method of treatment is to paint both lids at once with a 1 or 2 per cent. solution, depending on the severity of the attack. In a case seen early, this treatment is invaluable for cutting short the duration of the attack, and there is no doubt that the instillation of drops, apart from the painting of the lids, loses much valuable time. For some time it has been my practice to paint these cases directly they come to me, and the results have been superior to those of any ather type of treatment. The best way to apply the solution as a paint is to use a fine probe, such as that employed for the nasal duct, and, after winding a very thin piece of cotton-wool round one end, dip it into a receptacle holding perhaps ten drops of the solution; this prevents undue saturation of the cotton-wool, and if the painting is done carefully none need get on to the patient's lids. Apart from the acute cases of conjunctivitis, painting with a 2 per cent. mercurochrome is invaluable in those chronic cases in which there is a good deal of velvety thickening of the conjunctiva. This is the type of case that is so often beneficially treated with silver nitrate, or one of the silver compounds, but we have found mercurochrome superior to silver in that its irritation is considerably less (therefore it can be applied at more frequent intervals), that it cannot damage the cornea, and that there is no danger of staining the conjunctiva even if the drug be used over a very long period. It is our practice to treat this type of case with 